\title{
Contextualising gamification in the case of supply chain management
}

\author{
G. T. Tsoulfas
}

Technological Education Institution of Sterea Ellada, Department of Logistics Management

\begin{abstract}
Gamification is a concept that has received much attention lately and has found fertile ground for application in several disciplines, such as education and management. The main scope of gamified activities is to increase motivation and engagement, while providing an environment which facilitates learning, collaboration and the development of various skills. In the case of management so far gamification is mainly aimed at providing solutions within the boundaries of organisations (e.g. training) and/or with regard to the cooperation with individual stakeholders (e.g. customers). The academic studies on gamification are rather limited and the hype surrounding it is mostly based on successful implementations by prestigious organisations. This paper reviews the application of gamification in managerial functions and investigates the extension of its exploitation in the case of supply chain management. The goal is to provide a conceptual framework and valuable insights on how gamification can facilitate the efficient and effective operation of supply chains. Moreover, potential areas of application are identified along with the emerging benefits and the risks considering different supply chain typologies, which are distinguished based on various supply chain characteristics.
\end{abstract}

\section{Introduction}

This paper tries to build bridges between two different concepts that concern academics and the business world: gamification and supply chain management.

Gamification has gained much attention during the past decade and has been recognised as a useful approach among the academia and practitioners. The main idea behind gamification is to employ game elements in order to develop an inspiring, addictive, stimulating and engaging environment in order to achieve certain organisational goals and scopes. According to the seminal work of Caillois (2001) (originally published in French in 1958), there is a clear distinction between game and play. In fact, Caillois suggested the use of a continuum from ludus (structured activities with certain rules) to paidia (unstructured free-form activities). This major difference is the reason why we are talking about 'gamification' and not 'playfication' because from a designer's viewpoint it is critical to have a predefined set of pathways toward the achievement of certain goals. Of course, joy and fun are determinant parameters but as such they are used in order to improve the perceived experience.

Supply chain management is a growing and evolving discipline that enhances competitive advantage by connecting and coordinating business processes, activities and operations within and across partners. Supply chain management has acted as an aggregator of various scientific fields such as general management, operations management, marketing, strategic management and information technology.

The goal of this paper is to build on existing approaches on gamification and supply chain management in order to investigate how gamification can facilitate the efficient and effective operation of supply chains. Moreover, potential areas of application are identified along with the emerging benefits and the risks considering different supply chain typologies, which are distinguished based on various supply chain characteristics. In chapter 2 some insights on 
$8^{\text {th }}$ International Conference on Management, Economics and

Humanities

7 - 9 December, 2018

Barcelona, Spain

gamification are provided focusing on definitions, game elements, frameworks of analysis and relevant applications. In chapter 3 the major characteristics of supply chains and their role in contemporary business environment are outlined followed by a discussion on supply chain integration. In chapter 4 it is examined whether there is ground for the use of gamification in supply chain management. The paper ends with some concluding remarks.

\section{Insights on gamification}

\subsection{Gamification and game elements}

Although the term 'gameification' was originally coined by Terill (2008) in a blog post about the 2008 Social Gaming Summit, it had been already used in several settings, such as loyalty programmes and employees leaderboards. Deterding et al. (2011) define gamification as "the use of design elements characteristic for games in non-game contexts" in their effort to contrast gamification against other concepts such as serious games, toys and playful design. Werbach (2014) suggested that "gamification is the process of making activities more game-like". According to Huotari and Hamari (2017), "gamification refers to a process of enhancing a service with affordances for gameful experiences in order to support users' overall value creation". It is evident that earlier definitions were striving to establish gamification as a concept which uses game elements but is not a game on its own. In the last definition the focal point are the goals and scope of gamification and not the methods used to achieve it.

Warmelink et al. (2018) state that there are two basic dimensions regarding gamification: an internal dimension aiming at the users' entertainment or enjoyment; and an external dimension aiming at certain consequences. In their highly cited paper Deterding et al. (2011) distinguish and define five levels of game design elements: game interface design patterns (badge, leaderboard, level); game design patterns and mechanics (time constraint, limited resources, turns); game design principles and heuristics (enduring play, clear goals, variety of game styles); game models (Mechanics-Dynamics-Aesthetics framework; challenge, fantasy, curiosity; game design atoms; Core Elements of the Gaming Experience model); and game design methods (playtesting, playcentric design, value conscious game design). All those elements are met in most games and have a crucial role in gameplay. Moreover, it does not make sense to consider those elements in isolation without identifying the linkages among them.

\subsection{Frameworks of analysis and applications of gamification}

In the recent literature there have been proposed several frameworks for gamification. Mora et al. (2015) present a thorough analysis of them and then categorise them according to three criteria: background (academic vs non-academic); scope (complete vs focused); and approach (generic vs business-specific). Of course, all those frameworks have something new to offer to the field and may address alternative and complementary perspectives. Depending on the particularities of the situation under consideration analysts may choose the frameworks that suit better their needs. The generic frameworks that seem to have gained wide recognition are the 6D framework (Werbach and Hunter, 2012) and the Octalysis framework (Chou, 2015) (originally presented in his website in 2013).

The first step in the 6D framework is about the definition of business objectives. After that, the expected behaviours are outlined followed by the description of the players. Next, the activity loops 
$8^{\text {th }}$ International Conference on Management, Economics and

Humanities

7 - 9 December, 2018

Barcelona, Spain

are planned in order to define how the gamified system is expected to evolve. Moreover, Werbach and Hunter remind to us not to forget to add fun to the design of a gamified system before the last step of implementation, which is about selecting the tools to use.

The Octalysis framework is based on major drives that motivate humans. In this case eight different drives are identified. 'Epic meaning and calling' is about having the perception of contributing to an important mission. 'Development and accomplishment' is essentially about competitiveness and progress, whereas 'empowerment of creativity \& feedback' has to do with enforcing ingenuity and experimentation. 'Ownership and possession' is about gaining and managing some kind of valuable and exchangeable intangible assets, while 'social influence and relatedness' has to do with all social characteristics that may drive people. 'Scarcity and impatience' builds on people getting passionate and wanting to get access to something that they think only privileged can get. 'Unpredictability and curiosity' is about exploring the unknown and getting fascinated about how the activity evolves. Finally, 'loss and avoidance' is closely related to the feeling of lost opportunities. Chou adds that 'sensation' is a ninth hidden core drive, which complements the framework. Apparently, motivation is accomplished with different game elements and techniques for each of the above drives.

Another interesting framework which has not yet gained wide acceptance among the academia and practitioners is Marczewski's Player and User Types Dodecad (Marczewski, 2015). This is an extended version of his initial User Types Hexad. In the first place, Marczewski combines the selfdetermination theory by Ryan and Deci (2000), which posits three universal psychological needs (autonomy, competence, and relatedness) and the approach of Pink (2009) according to which the intrinsic motivators are autonomy, mastery, purpose. This combination led to the so-called 'intrinsic motivation RAMP' (relatedness, autonomy, mastery, purpose). Then, Marczewski identifies three broad categories of users: intrinsic, players and disruptors. Intrinsic users are intrinsically motivated and constitute the most important category. Ideally, analysts should seek ways to convert other user types to this category. Players are actually motivated by rewards, so the challenge is to engage them so that they get intrinsically motivated. Disruptors may offer opportunities for significant improvements to the system, but they may also be the source of major problems. For each of the above categories there are four user types, which are presented in Table 1.

The Octalysis framework and the Player and User Types Dodecad suggest that it is necessary to incorporate a blend of different features in order to enhance participants' engagement. Herbert et al. (2014) provide relevant empirical evidence in the analysis of their gamified learning system.

There is a wide area of gamification applications in several disciplines in order to achieve certain organisational goals and scopes. Kasurinen and Knutas (2017) analysed 1,164 studies on gamification in order to identify and map the major trends in research and application. Their work revealed the categories with the major penetration of gamification. Their top 10 is as follows:

1. Computer science education

2. Motivation

3. Ecology and sustainability

4. Software development

5. Social behaviour

6. STEM fields other than computer science

7. Physiotherapy

8. Management

9. E-government

10. History \& museums 
It should be noted that gamification should not be regarded as panacea in order to achieve organisational goals and scopes. Hamari et al. (2014) underline that although gamification may indeed be useful in many occasions, this is dependent on the context in which it is used, as well as on the users using it. In addition, efficient design and planning is a major prerequisite for the positive results from gamification.

Table 1. User styles

\begin{tabular}{|l|l|l|l|}
\hline & Intrinsic & Players & Disruptors \\
\hline Relatedness & Socialiser & Networker & Influencer \\
\hline Autonomy & Free Spirit & Exploiter & Innovator \\
\hline Mastery & Achiever & Consumer & Destroyer \\
\hline Purpose & Philanthropist & Self-Seeker & Griefer \\
\hline
\end{tabular}

\section{Supply chain management}

\subsection{The emergence and the rising role of supply chains}

Carter et al. (2015) proposed six premises about the structure and boundary of the supply chain. Those premises may be used as axioms for theoretical developments and practical implications in supply chain management:

- The supply chain is a network, consisting of nodes and links.

- The supply chain as a network operates as a complex adaptive system, where every agent grapples with the tension between control and emergence.

- The supply chain is relative to a particular product and agent.

- The supply chain consists of both a physical supply chain and a support supply chain.

- The supply chain is bounded by the visible horizon of the focal agent.

- The visible horizon of the focal agent is subject to attenuation, where distance is based on factors including physical distance, cultural distance, and closeness centrality.

According to Christopher (2016) supply chain management is "the management of upstream and downstream relationships with suppliers and customers in order to deliver superior customer value at less cost to the supply chain as a whole". In a way this definition accommodates the concept of competitive advantage as identified by Porter (1985). In that book Porter also introduced the concept of the value chain which refers to the sequence of primary activities that aim in value creation through the efficient use of resources while being backed by a set of support activities. The primary activities in the generic value chain are inbound logistics; operations; outbound logistics; marketing and sales; and service. The support activities are infrastructure; technological development; human resources management; and procurement. Mentzer et al. (2001) suggested that supply chain management entails the following traits: a systems approach according to which the supply chain is treated as a whole; a strategic orientation toward cooperation and synchronisation of the parties involved; and a customer focus aiming at creating customer value and enhancing customer satisfaction.

Ambe (2012) reviewed several typologies and frameworks which have been proposed for the analysis of supply chains in 31 different publications. Then he developed an integrated framework where he classified the criteria for determining supply chain strategies and practices into three main categories: the characteristics of the product (discussed in 25 out of 31 of the above publications); 
$8^{\text {th }}$ International Conference on Management, Economics and

Humanities

7 - 9 December, 2018

Barcelona, Spain

the manufacturing characteristics (discussed in 14 out of 31 of the above publications); and the decision drivers of supply chains (discussed in 4 out of 31 of the above publications). Each individual criterion may be evaluated using a continuum of attributes. The ends of the continuum correspond to lean and agile supply chains. Eventually, all other available options would fit in leagile supply chains. The concepts of lean and agile supply chains stem from the homonym production approaches and share the same principles in a supply chain context. According to Ben Naylor et al. (1999) "agility means using market knowledge and a virtual corporation to exploit profitable opportunities in a volatile market place" while "leanness means developing a value stream to eliminate all waste, including time, and to ensure a level schedule". The supply chain paradigm that will be selected by the focal firm will actually dictates the requirements and the characteristics for all other parties involved.

\subsection{Supply chain integration}

O'Leary-Kelly and Flores (2002) gave a general definition on integration through a management lens: "the level of integration refers to the extent to which separate parties work together in a cooperative manner to arrive at mutually acceptable outcomes". This definition can be used in the case of supply chain integration, which is aims at the close cooperation and coordination of supply chain partners in all kinds of activities and operations.

Van der Vaart and van Donk (2008) analysed extensively the relationship between supply chain integration and performance. Moreover, they proposed a model which considers attitudes, patterns and practices as well as their interrelationships in order to shape buyer-supplier relationships. This triptych is influenced by power distribution and business conditions. Leuschner et al. (2013) proposed to use three dimensions to compare and contrast supply chain integration on firm performance:

- Information integration which is about coordinating information exchange and communication.

- Operational integration which is about the development of joint activities and the coordination of decision-making.

- Relational integration which is about building strategic alliances and embrace long- term orientation.

It should be noted that each dimension builds on the previous one(s). Their model is based on various organisational theories including the resource- based view and the relational view which comprise the foundations of strategic management.

Flynn et al. (2008) argue that supply chain integration is essentially about three dimensions: customer, supplier and internal integration. The first two dimensions are parts of the external integration, which aims at transforming practices and processes in a way that collaboration, coordination and synchronization are facilitated. On the other hand, the subject of internal integration is to achieve the above targets at organisational level by focusing on the organisation's own practices and processes. In addition, Flynn et al. (2008) empirically validated the relationship between supply chain integration and performance.

Kannan and Tan (2010) studied the case of supply chain integration beyond first tier suppliers and customers. Their major finding is that a broad span of integration has indeed positive impact, so organisations should include more stakeholders in their integration efforts. Moreover, significant opportunities may arise, and the competitive advantage of supply chains is improved.

Prajogo and Olhager (2012) studied and empirically validated the relationship between supply chain integration and performance with regard to long-term relationships, information technology 
and sharing, and logistics integration. They also concluded that long-term relationships are a prerequisite for supply chain integration given its complexity.

\section{Is there ground for gamification in supply chain management?}

For the successful implementation of supply chain management several activities have been identified (Mentzer et al., 2001):

- Integrated Behaviour

- Mutually Sharing Information

- Mutually Sharing Risks and Rewards

- Cooperation

- The Same Goal and the Same Focus on Serving Customers

- Integration of Processes

- Partners to Build and Maintain Long-Term Relationships

All the above activities are still valid even though this paper was published back in 2001. If we had to add something new to the above list that would be innovation. Since competition is now taking place at a supply chain level, it is important to be able to innovate as a whole system. In particular, the concept of open innovation seems to be suitable in many supply chain operations. Enkel et al. (2009) identified three core processes for open innovation:

- the outside-in process which is about improving the organization through the inclusion of external knowledge and the integration of suppliers and customers

- the inside-out process which is about introducing new ideas to market and reaping the corresponding rewards

- the coupled process which is about the co-creation with partners through cooperation.

Focal organisations have a significant role to play in open innovation since they are responsible for the coordination of all involved parties. Moreover, this is getting even more crucial as disruptive innovations emerge. Being part of Industry 4.0, Logistics 4.0 and Supply Chain Management 4.0 indicate the new era in logistics and supply chain management through the development and adoption of emerging technologies.

According to Werbach and Hunter (2012) gamification emerges in three forms:

- Internal gamification - It is about creating a gamified environment which aims at certain goals within the organisation. That is to say organisations seek ways to improve the potential of their human capital in terms of engagement, productivity, skills and capabilities, knowledge, etc.

- External gamification - In this case organisations appeal to customers or prospective customers aiming at improved relationships and stronger loyalty which are expected to help the organisation to achieve its business goals.

- Behaviour change gamification - It is about contributing to the change of attitudes and habits of people, so this is clearly a kind of social intervention. This form is expected to be fostered by governmental, non-governmental and not-for-profit organisations.

The above distinction is not sufficient in the case of supply chains, since it does not leave ground for addressing several categories of stakeholders. Moreover, the above typology seems to be oriented to B2C markets and does not address the particularities met in B2B markets. Apart from the dyadic relationships which are developed in a supply chain context there are also relationships which may involve more than two parties or even all of them. In such cases it is necessary to 
$8^{\text {th }}$ International Conference on Management, Economics and

Humanities

7 - 9 December, 2018

Barcelona, Spain

develop shared codes of conduct in order to coordinate activities. Thus, in the case of supply chains it is necessary:

- to extend the boundaries of external gamification so that it includes all kinds of relationships with various stakeholders.

- to add the form of organisational behaviour change gamification so that it incorporates all changes in the ways supply chain partners cooperate and interact in order to respond to the specific requirements of supply chains.

By definition, gamification aims at providing an interactive, engaging and innovative environment. Those characteristics are inherent in efficient supply chain planning and operation. Moreover, gamified applications attempt to accommodate various types of players with different motivation and characteristics. This is also a trait of supply chains. Therefore, it seems that there is fertile ground for gamified applications in supply chain management because they can foster the successful implementation of supply chain activities and enhance supply chain integration, which is a major desideratum as discussed in section 3.2. In addition, supply chains are closely related to sustainability considerations, which comprise a popular topic of gamified applications. The connection of supply chains with sustainability is dual and the following two dimensions are interrelated:

- All supply chains processes are subjected to changes toward their adjustment in the new landscape, particularly the demand for sustainability.

- Owing to their nature, supply chains serve as a means to support sustainability purposes (closing materials cycles).

However, it should be noted that the existing literature which connects supply chain management with gamification is extremely limited. In fact, it seems that relevant applications have been developed in educational contexts (see e.g. Wood and Reiners, 2012; Reiners et al., 2013; Lau, 2014) and not in business environments. The fact that Warmelink et al. (2018) present a rather limited penetration of gamification in production and logistics operations also indicates that the use of gamification in supply chains is still in its infancy.

\section{Concluding remarks}

It is clear that the outputs of a gamified activity are highly dependent on the participants. Therefore, the exhaustive analysis of alternative types of players is necessary in order to facilitate the design of such activities and make them attractive to as many as possible. Naturally, it is difficult to accommodate all participants' wants, needs and drives. This would lead to a complex system as an end in itself, which could not respond to the requirements of organisations. In this case it is better to decompose the goals into manageable parts that are easier to comprehend and tackle, and then set less ambitious targets. Moreover, the role of participants in organisations and supply chains is of varying importance. For example, for some it is a strategic priority to be part of a given supply chain while for others it is just an occasion. In this case focal organisations should narrow the scope of gamified activities and focus on how they can build efficient and long-lasting relationships with their partners. Another possible risk is the lack of orientation as the gamified activity evolves. The more complex the scenario, the more difficult to maintain control and to stay aligned with the scope. In addition, the lack of trust in supply chain management may be a major obstacle since it will result in inefficient and ineffective performance in all kinds of joint activities. Of course, gamification can be used in order to build trust among business partners 
$8^{\text {th }}$ International Conference on Management, Economics and Humanities

7 - 9 December, 2018

Barcelona, Spain

Needless to say, an organisational culture which fosters innovation and continuous development is a prerequisite for successful gamification projects. Besides, innovative organisations strive to go far beyond to uncharted areas seeking for blue oceans and white spaces.

As stated earlier, the use of gamification in supply chains is still in its infancy. Thus, it is important to work on empirical data in order to perform an integrated needs analysis. It is expected that this will point out the priorities that have to be considered as well as the preparatory activities that must be carried out by supply chain partners.

\section{References}

1. Ambe, I.M.: 'Determining an Optimal Supply Chain Strategy', Journal of Transport and Supply Chain Management, 6(1), 126-147, 2012

2. Ben Naylor, J., Mohamed M. Naim, and Danny Berry.: 'Leagility: Integrating the Lean and Agile Manufacturing Paradigms in the Total Supply Chain', International Journal of Production Economics 62(1-2), 107-118, 1999

3. Caillois, R.: Man, play and games, University of Illinois Press, 2001

4. Carter, C.R., Rogers, D.S. and Choi, T.Y.: 'Toward the Theory of the Supply Chain', Journal of Supply Chain Management, 51(2), 89-97, 2015

5. Chou, Y.-K.: Actionable Gamification: Beyond Points, Badges, and Leaderboards, Octalysis Media, 2015

6. Christopher, M.: Logistics \& Supply Chain Management, $5^{\text {th }}$ ed., FT Press, 2016

7. Deterding, S., Dixon, D., Khaled, R. and Nacke, L.: 'From Game Design Elements to Gamefulness' in proceedings of the $15^{\text {th }}$ International Academic MindTrek Conference on Envisioning Future Media Environments - MindTrek '11, 9-15, Tampere, Finland, September 28-30, 2011

8. Enkel, E., Gassmann, O. and Chesbrough, H.: 'Open R\&D and Open Innovation: Exploring the Phenomenon', $R \& D$ Management, 39(4), 311-316, 2009

9. Flynn, B.B., Huo, B. and Zhao, X.: 'The Impact of Supply Chain Integration on Performance: A Contingency and Configuration Approach', Journal of Operations Management, 28(1), 58-71, 2010

10. Hamari, J., Koivisto, J. and Sarsa, H.: 'Does Gamification Work? - A Literature Review of Empirical Studies on Gamification', in proceedings of the $47^{\text {th }}$ Hawaii International Conference on System Science, 3025-3034, Waikoloa, Hawaii, USA, January 6-9, 2014

11. Herbert, B., Charles, D., Moore, A. and Charles, T.: 'An Investigation of Gamification Typologies for Enhancing Learner Motivation', in proceedings of the 2014 International Conference on Interactive Technologies and Games, 71-78, Nottingham, United Kingdom, October 16-17, 2014

12. Huotari, K. and Hamari, J.: 'A Definition for Gamification: Anchoring Gamification in the Service Marketing Literature', Electronic Markets, 27(1), 21-31, 2017

13. Kannan, V.R. and Tan, K.C.: 'Supply Chain Integration: Cluster Analysis of the Impact of Span of Integration', Supply Chain Management: An International Journal, 15(3), 207-215, 2010

14. Kasurinen, J. and Knutas, A.: 'Publication Trends in Gamification: A Systematic Mapping Study', Computer Science Review, 27, 33-44, 2018

15. Lau, A.K.W.: 'Teaching Supply Chain Management Using a Modified Beer Game: An Action Learning Approach' International Journal of Logistics Research and Applications, 18(1), 62-81, 2015

16. Leuschner, R., Rogers, D.S. and Charvet, F.F.: 'A Meta-Analysis of Supply Chain Integration and Firm Performance', Journal of Supply Chain Management, 49(2), 34-57, 2013

17. Marczewski, A.: Even Ninja Monkeys Like to Play: Gamification, Game Thinking and Motivational Design, Blurb, 2015

18. Mentzer, J.T., DeWitt, W., Keebler, J.S., Min, S., Nix, N.W., Smith, C.D. and Zacharia, Z.G.: 'Defining Supply Chain Management', Journal of Business Logistics, 22(2), 1-25, 2001

19. Mora, A, Riera, D., Gonzalez, C. and Arnedo-Moreno, J.: 'A Literature Review of Gamification Design Frameworks', in proceedings of the 7th International Conference on Games and Virtual Worlds for Serious Applications (VS-Games), 1-8, Skovde, Sweden, September 16-18, 2015 
$8^{\text {th }}$ International Conference on Management, Economics and Humanities

7 - 9 December, 2018

Barcelona, Spain

20. O’Leary-Kelly, S.W. and Flores, B.E.: 'The Integration of Manufacturing and Marketing/Sales

Decisions: Impact on Organizational Performance', Journal of Operations Management, 20(3), 221-240, 2002

21. Pink, D.H.: Drive: The Surprising Truth About What Motivates Us, Riverhead Books, 2009

22. Porter, M.H.: Competitive Advantage: Creating and Sustaining Superior Performance (Republished with a New Introduction, 1998), Free Press, 1985

23. Prajogo, D. and Olhager, J.: 'Supply Chain Integration and Performance: The Effects of Long-Term Relationships, Information Technology and Sharing, and Logistics Integration', International Journal of Production Economics, 135(1), 514-522, 2012

24. Ryan, R.M. and Deci, E.L.: 'Self-Determination Theory and the Facilitation of Intrinsic Motivation, Social Development, and Well-Being', American Psychologist, 55(1), 68-78, 2000

25. Terrill, B.: 'My Coverage of Lobby of the Social Gaming Summit', online, http://www.bretterrill.com/2008/06/my-coverage-of-lobby-of-social-gaming.html, retrieved October 20, 2018

26. Van der Vaart, T. and van Donk, D.P.: 'A Critical Review of Survey-Based Research in Supply Chain Integration', International Journal of Production Economics, 111(1), 42-55, 2008

27. Warmelink, H., Koivisto, J., Mayer, I., Vesa, M. and Hamari, J.: 'Gamification of Production and Logistics Operations: Status Quo and Future Directions', Journal of Business Research, forthcoming

28. Werbach, K: ' $(\mathrm{Re})$ Defining Gamification: A Process Approach', in proceedings of the $9^{\text {th }}$ International Conference, PERSUASIVE 2014, 266-272, Padua, Italy, May 21-23, 2014

29. Werbach, K. and Hunter, D.: The Gamification Toolkit Game Elements, Wharton Digital Press, 2012

30. Wood, L.C. and Reiners, T.: 'Gamification in Logistics and Supply Chain Education: Extending Active Learning', IADIS Internet Technologies and Society, 2012 